Gendered academic adjustment among Asian American adolescents in an emerging immigrant community.

By: Lisa Kiang, Andrew J. Supple, Gabriela L. Stein and Laura M. Gonzalez

Kiang, L., Supple, A. Stein, G.L., \& Gonzalez, L. (2012). Gendered academic adjustment among Asian American adolescents in an emerging immigrant community. Journal of Youth and Adolescence, 41, 283-294.

Made available courtesy of Springer Verlag. The original publication is available at http://link.springer.com/article/10.1007/s10964-011-9697-8/fulltext.html.

***Reprinted with permission. No further reproduction is authorized without written permission from Springer Verlag. This version of the document is not the version of record. Figures and/or pictures may be missing from this format of the document. ***

\begin{abstract}
:
Research on the academic adjustment of immigrant adolescents has been predominately conducted in large cities among established migration areas. To broaden the field's restricted focus, data from 172 (58\% female) Asian American adolescents who reside within a nontraditional or emerging immigrant community in the Southeastern US were used to examine gender differences in academic adjustment as well as school, family, and cultural variables as potential mediators of gender differences found. Results suggest that girls report significantly higher educational goals, intrinsic academic motivation, and utility value of school compared to boys. These gender differences are statistically mediated by ethnic exploration and family processes, most prominently, family respect. School connectedness and perceived discrimination are also associated with academic adjustment at the bivariate level, suggesting that academic success may be best promoted if multiple domains of influence can be targeted.
\end{abstract}

Keywords: gender | academic adjustment | Asian adolescents | immigrants | immigrant communities | adolescents

Article:

Introduction

Adolescents from ethnic minority backgrounds will soon comprise over $50 \%$ of the US schoolaged population, and the fastest growing proportions of these youth are children of immigrants or immigrants themselves (US Census 2004). Although much of the research on academic adjustment has tended to disregard ethnicity altogether (Brown and Evans 2002), some work suggests that adolescents from immigrant families are at risk for experiencing academic challenges due to migration itself, cultural adjustment difficulties, language barriers, and 
discrimination (Suárez-Orozco et al. 2009; Suárez-Orozco et al. 2010). What is more, research on adolescents from immigrant families suggests that, compared to girls, boys are especially vulnerable to poor academic outcomes, such as low motivation, achievement, and attainment (Qin 2006). As possible mechanisms to explain such gender gaps, Qin (2003) posited that gender differences in parental expectations, family relationships, socialization experiences, and peer relationships may be conceptually linked to gendered academic adjustment. However, there have been few empirical tests of the significance of such factors as statistical mediators of gender effects. Further, virtually all of the research on the educational well-being of immigrant youth has been conducted in large, urban areas, such as New York or Los Angeles. Whether academic gender gaps are found in emerging immigrant communities (e.g., areas of the US that are newly becoming accustomed to hosting immigrant families) remains a key empirical question. The goal of the current research was to address these limitations by (1) examining evidence for gendered patterns of adolescent academic adjustment, broadly defined via goals, expectations, intrinsic motivation, and attitudes toward school, among an understudied emerging immigrant community, and (2) identifying process-oriented school, family, and cultural variables as specific factors related to academic adjustment, and as possible mediators of gender effects.

In examining these issues, we focus on Asian American youth who are understudied in the field despite comprising one of the fastest growing ethnic groups in the US (US Census 2011). Given that adolescents' academic experiences can determine downward trajectories or long-term success (Eccles et al. 1993), and that educational achievement is a primary route by which immigrant youth can effectively adapt and promote their family's socioeconomic mobility (Zhou and Bankston 2001), it is particularly crucial to examine the nature of Asian adolescents' educational success. However, these youth are often overlooked in the academic arena given the hazardous assumption that they are the "model minority" and well-adjusted (Chun 1995; Suzuki 2002). School personnel and teachers may hold stereotypes that characterize Asians as smart, quiet, and having few problem behaviors, which may render any academic or psychosocial struggles relatively invisible (Ngo and Lee 2007; Wong and Halgin 2006). For some, academic setbacks may be especially stressful because, culturally, Asian parents may emphasize success and participation in academic domains more so than in other areas (e.g., extracurricular activities, peers) (for a nuanced review, see Sue and Okazaki 1990). In sum, we consider the extent to which gender differences in academic outcomes (including putative explanations) are found in understudied Asian immigrant youth residing in an understudied geographic setting, thereby better understanding how diverse factors in adolescents' lives can challenge or promote their academic adaptation.

Gender Gaps in Academic Adjustment in Emerging Immigrant Communities

Contemporary research has targeted gender as having a key role in structuring immigrant youths' adaptation and adjustment, including their academic experiences (Portes and Rumbaut 2001; Qin 
2006; Suárez-Orozco and Qin 2005). For instance, among immigrants from Asian, Latin American, and Afro-Caribbean backgrounds, girls typically academically outperform and attain higher education levels than boys (e.g., Rong and Brown 2001; Brandon 1991). In one of few longitudinal studies to track the academic trajectories of immigrant youth over time (SuárezOrozco et al. 2010), girls reported higher average levels of academic engagement and achievement, measured through GPA, than boys, were more likely to be consistently high achieving, and were less likely to precipitously decline in achievement. However, one notable limitation to existing research is its near exclusive focus on adolescents from metropolitan cities (e.g., New York) where the surrounding community is ethnically diverse and resources encouraging immigrant adolescents’ growth may already exist.

Recent changes in US immigration patterns have led to dramatic and rapid increases in the foreign-born population among specific geographic regions. Growth in immigrant and refugee populations has been especially dramatic in the Southeastern US. The state of North Carolina, for example, experienced a 274\% increase in its foreign-born population during the $1990 \mathrm{~s}$ and a 49\% increase from 2000-2008 (ranking 1st and 7th, respectively, among US states for highest growth; Migration Policy Institute, 2008). With these sudden population changes comes the need to understand social patterns of development, especially for the newcomer families who are changing the demographics in these non-traditional or emerging areas of settlement.

Among these new communities, educators face challenges in understanding and addressing newcomer families’ needs (Bailey 2005). For instance, school counseling services for adolescents in new immigrant communities tend to pragmatically center on language issues, yet overlook more general cultural difficulties that also influence adjustment (Dotson-Blake et al. 2009; Smith-Adcock et al. 2006). Recent qualitative work similarly suggests that adolescents who moved from urban areas with large Hmong populations to emerging immigrant communities reported feeling ignored by school personnel in their new environments and received direct and indirect messages that doubted their academic success (Supple et al. 2010). Often due to limited infrastructure and knowledge on behalf of school and community members, institutional and educational supports for adolescents in emerging immigrant receiving areas may be underdeveloped (Bailey 2005). Hence, new settlement areas may impart qualitatively distinct experiences for youth given the contextual and social obstacles that can hinder their adaptation (Perreira et al. 2010), emphasizing the need to extend empirical work to adolescents from these communities.

Focusing specifically on youth residing in new immigrant communities may therefore broaden the generalizability of existing research. With a near exclusive focus on adolescents residing in traditional areas of migration, our understanding of immigrant youth development has been limited to regions that tend to be metropolitan and ethnically diverse. With respect to Asian Americans, those who are studied in existing work are commonly from East Asian backgrounds (e.g., Chinese, Korean), whereas youth from emerging immigrant communities may be more heterogeneous and more often represent Southeast Asian countries (e.g. Laos, Cambodia, 
Vietnam) (Massey and Capoferro 2008). Recent research suggests that Southeast Asian youth may face distinct, and often less adaptive, experiences than their other Asian counterparts and should be further examined to extend the current literature (Portes and Rumbaut 2001). In addition to ethnic ancestry, families settling in emerging immigrant communities may have different educational backgrounds and incomes than their counterparts in other areas.

Historically, increased saturation in traditional gateway cities and nationwide shifts in low-wage, low-skill industries (e.g., meatpacking, textiles) from larger cities to smaller towns have, in part, contributed to recent migration shifts (Parrado and Kandel 2008). Families who settle in new immigrant communities, perhaps seeking opportunities among such industries, may thus have unique sociodemographic characteristics compared to those typically studied in more urban areas.

Theoretical perspectives from Bronfenbrenner (1979) clearly argue that environmental context plays an important role in development. As such, there is an urgent need to examine the development of immigrant youth among understudied environmental contexts, especially since existing research has had a limited focus on specific ethnic groups (e.g., East Asian) within specific regions of the US (e.g., large, urban cities). By focusing on emerging immigrant communities, the current study contributes to the field by targeting youth from an understudied geographic context who may represent more diverse sociodemographic backgrounds than those who have been commonly studied. Gender differences in academic outcomes are examined, as well as putative mediators to help explain gendered patterns of adjustment.

Putative Mediators of Gendered Academic Adjustment

Mediators of gendered academic adjustment have yet to be systematically quantified. However, theoretical and qualitative work suggests that gendered socialization experiences may exist at school, at home, and culturally, particularly among adolescents from immigrant families. In the following sections, we outline the possibility that experiences and interactions among different contexts (e.g., school, home) and cultural experiences related to ethnic identity may vary by gender which, in turn, could help to explain gender differences in academic adjustment.

Gendered Relations at School

From an ecological perspective (Bronfenbrenner 1979), schools shape development at a daily, microsystemic level, and positive or negative school experiences ultimately structure adolescents' decisions to commit to their education and achieve. School connectedness, at a broad level, refers to students' feelings of school acceptance and support, and promotes positive outcomes including lower drop-out rates, depression, and drug use, and higher self-esteem, selfefficacy, and well-being (Roeser et al. 2000; Way and Robinson 2003). Supportive and 
respectful student-teacher relationships can contribute to students’ school connectedness, promoting high grades and motivation, and hindering behavioral problems and attrition (LaRusso et al. 2008; Ryan and Patrick 2001; Klem and Connell 2004), suggesting that students who believe that teachers value and care about them feel more invested and academically engaged (Marchant et al. 2001).

Adolescents from immigrant and refugee families often face language barriers and cultural stress that can impede their school connection (Xiong et al. 2005), and these experiences may be magnified in emerging immigrant communities. For instance, youth may sense cultural distance from school due to their family's background, socioeconomic standing, or parental restrictions on behaviors that may be perceived as overly controlling. Moreover, peers and school personnel may stereotype some Asian immigrants as “model minorities” due to high achievement, or as “delinquents" due to gang involvement (Lee and Stacey 2001). Taken a step further, perceptions of discrimination stemming from teachers and students could also hinder academic success. All of these factors likely lead to low perceptions of school connection and, in turn, failure and high dropout rates (Yang 2003).

Gender differences in school experiences, such as those outlined above, have been found with boys reporting more achievement barriers than girls. Boys from immigrant families tend to report greater mistrust of and conflict with teachers and school personnel while also exhibiting lower scholastic engagement, motivation, and school connection than girls (Stanton-Salazar 2001; Suárez-Orozco and Qin 2005). School staff may also have different expectations regarding adolescents’ success (Lopez 2003; Suárez-Orozco and Qin 2005). Consistent with the classic perspectives of symbolic interactionism (e.g., Cooley 1902), biases against boys and positive expectations of girls could motivate differential treatment and attitudinal evaluations that are internalized by adolescents, ultimately contributing to gendered academic adjustment. Indeed, teachers tend to perceive qualities that are associated with academic success (e.g., cooperative, disciplined) among girls whereas boys tend to be perceived as having qualities linked with low achievement (e.g., lack of self-control, uncooperative), thus reflecting the idea of school as a feminized experience (Lane et al. 2003; Lopez 2003).

A collection of school experiences may thus reflect key mediators of gender differences in academic outcomes. Specifically, in the current study, we expected girls to report higher levels of school connectedness and attachment than boys. Two indices were considered including school centrality, or the degree to which individuals feel that school represents an important part of the self, and a broad indicator of connectedness reflecting feelings of being valued and affiliated with school. In turn, these positive school experiences were expected to relate to more positive academic adjustment. Main and mediating effects of perceived discrimination, presumably experienced within the school context, were also explored.

Gendered Relations at Home 
Family socialization messages that vary by gender may also explain differential patterns of academic adjustment. Culturally, many Asian American families tend to more strictly control and monitor girls’ behaviors than boys' (Qin 2003). Greater monitoring may lead to more parental knowledge about girls' academic lives relative to boys, as well as minimize girls' exposure to risky contexts and encourage their concentration on academics (Zhou and Bankston 2001). Alternatively, strict control at home may have an indirect consequence such that girls feel invested and simply gain pleasure from school as a context with greater freedom and less social constraints (Olsen 1997). While some may resent such control, the close family contact may ultimately engender feelings of parental connection and support. Moreover, if parental contact leads to greater connectedness, for instance, through positive parent-child relationships, respect, or family obligation, higher academic adjustment may be also expected (Fuligni et al. 1999). Given that girls tend to be socialized toward family closeness more than boys, and may also receive greater parental attention, family-oriented variables may represent additional mediators of gendered academic outcomes.

Gendered Cultural Experiences

Girls from immigrant families are often strongly socialized to be primary transmitters of cultural values and traditions (Supple et al. 2010). Perhaps due to ethnic socialization differences, girls may feel more strongly connected to their ethnic background than boys (Qin 2003). In turn, strong ethnic identification among immigrant youth has been positively linked to academic adjustment (Fuligni et al. 2005; Vargas-Reighley 2005). Parental expectations regarding the transmission of cultural values and adolescents' exposure to positive cultural interactions at home may thus specifically promote school success by encouraging a strong sense of ethnic identity (Supple et al. 2006). Ethnic identity may have a direct effect on academic achievement and motivation, such as when adolescents who identity strongly with their ethnic group tend to report more positive attitudes toward school (Fuligni et al. 2005), as well as an indirect effect. For instance, teachers tend to rate youth with high levels of ethnic identity as cooperative, further suggesting that ethnic identity may explain gender differences in academic experiences (Supple et al. 2006). Differential cultural socialization that emphasizes girls’ ethnic identity may subsequently relate to how youth feel about and how they are perceived in school, thereby serving as addition mediators of gender differences in academic adjustment.

The Current Study

Our overarching goal was to examine patterns of academic adjustment among youth from Asian American backgrounds who reside in an emerging immigrant community and represent a rapidly 
growing demographic that is vastly understudied in the literature. Given recent research documenting significant achievement gaps between boys and girls from immigrant families in more urban areas (Suárez-Orozco and Qin 2005), we first examined whether similar gaps would be found among our sample. We then considered variables from multiple domains (e.g., school, family, culture) as correlates of academic outcomes and as mediators of gender differences found.

Methods

Participants

Ninth (50\%) and tenth graders with Asian ancestry were recruited from six public high schools in the Southeastern US $(n=172)$. The average age was $14.97(\mathrm{SD}=.84)$. Females comprised approximately 58\% of the sample. Most adolescents were US-born or of the second generation (75\%). The remaining participants were foreign-born or first generation (25\%). Based on selfreport, adolescents represented several ethnic heritage groups: 28\% Hmong, 22\% multiethnic (mostly within Asian groups, e.g., Cambodian and Chinese), 11\% South Asian Indian, 8\% Chinese, 8\% panethnic (e.g., Asian), and the remaining 23\% represented small clusters such as Laotian, Montagnard, Pakistani, Thai, and Vietnamese.

The occupational and educational backgrounds of adolescents' parents reflected a relatively wide range, giving some insight on families' socioeconomic status. Adolescents' open-ended reports of their parents' jobs were coded into categories. Approximately $11 \%$ of fathers and $18 \%$ of mothers worked in untrained positions (housecleaning, factory worker), $14 \%$ and $10 \%$ were in semi-skilled professions (cashier, construction), 12\% and 15\% were in skilled professions (electrician, seamstress), 17\% of both fathers and mothers were in semi-professional work (nurse, small business owner), 14\% of fathers and 2\% of mothers were in professional work (engineer, physician), and 7 and 18\% were unemployed. The remaining 25\% of fathers and 20\% of mothers were coded as either missing, uncodable, or adolescents wrote “don't know”. In terms of education, $6 \%$ of fathers and $9 \%$ of mothers completed some elementary or junior high school, 6 and 8\% completed some high school, 12 and 9\% were high school graduates, 6 and 7\% completed some college, 21 and 20\% were college graduates, and 16 and 7\% completed graduate education. Notably, reports on parents' education were not very complete. Adolescents reported “don't know" for the remaining 33\% of fathers and $40 \%$ of mothers.

Procedure 
In small group settings, adolescents who were identified by their school as panethnically Asian were invited to participate in a study focusing on adolescents' daily lives and their thoughts on school, social relationships, and culture. Students were given assent and parental consent forms and those who returned these forms (approximately 60\%) completed a packet of questionnaires during a follow-up school visit. Questionnaires took about 40-50 min to complete and assessed a variety of constructs including academic and psychological adjustment, family relationships and values, cultural identity, and perceived discrimination. As an additional component to the study, students were given a 14 day supply of daily diary questionnaires to complete at home. The current study focused solely on single-survey items. Adolescents were given $\$ 25$ for participating in both the survey and daily diary portions of the study.

Measures

Four indicators of academic adjustment were considered, namely, academic goals, academic expectations, intrinsic motivation, and utility value of school. This set of measures was based on research from Eccles (1983) and has been used successfully in prior research (Fuligni et al. 2005). Putative mediators included multiple indicators of school (e.g., centrality, connectedness, perceived discrimination), family (e.g., respect, obligation), and cultural identity (e.g., belonging, exploration) variables.

Academic Goals

To assess goals, adolescents were asked, "How far would you like to go in school?” Response options were 1 = finish some high school, 2 = graduate from high school, 3 = graduate from a 2 year college, 4 = graduate from a 4 year college, 5 = graduate from law, medical, or graduate school.

Academic Expectations

One item was also used to assess expectations. Adolescents were asked, "How far do you think you actually will go in school?” Identical response options as for academic goals were used.

Intrinsic Motivation

Intrinsic motivation was measured using two items. Adolescents were asked, "In general, I find working on schoolwork..." ( 1 = very boring, 5 = very interesting). In addition, "How much do 
you like working on school work?” ( 1 = a little, 5 = a lot). These two items were significantly correlated $(r=.74, \mathrm{p}<.001)$.

Utility Value of School

Four items were used to assess utility value of school. Adolescents first reported on how important they think being in school is ( 1 = not at all important, $5=$ very important). They were also asked how useful they believe school is in their everyday life currently, for the future, and after graduating ( $1=$ not at all useful, $5=$ very useful). The internal consistency of these four items was .77.

School Centrality

To gauge the degree to which youth feel that their school and that going to school reflects a key component of the self, a school centrality scale was derived from the shortened Multidimensional Inventory of Black Identity (MIBI; Yip et al. 2006). Four items were rated on a scale of $1=$ strongly disagree to 5 = strongly agree. Sample items read, "In general, going to my school is an important part of my self-image", and, "Being a part of my school is an important reflection of who I am”. Similar adaptations of the MIBI to other social identity domains (e.g., religion, family) as well as to adolescents from immigrant backgrounds have been successful prior work (e.g., Fuligni et al. 2005; Kiang et al. 2008; Yip et al. 2006). The internal consistency was .82.

School Connectedness

A broad index of school connectedness was measured by responses to four items on a $1=$ strongly disagree to 5 = strongly agree scale. Items read, "I feel close to people at school”, "I feel like I am a part of my school”, “I feel like a valued member of my school”, and, "I do not feel like an important part of my school (reverse scored)”. The internal consistency was .79.

Perceived Discrimination

Adolescents were asked, "How often have you felt racial or ethnicity-based discrimination in the following situations”, using a list of seven events (e.g., being treated unfairly, being treated with less respect). On a 1 = never to 5 = all the time scale, adolescents indicated each event's frequency $(\alpha=.89)$. This measure was based on extensive qualitative research (Rosenbloom and Way 2004) and was developed for use with adolescents from diverse ethnic backgrounds (Greene et al. 2006). 


\section{Family Respect}

Family respect was assessed with a 7-item measure that has shown good reliability in ethnically diverse adolescents in prior research (Fuligni et al. 1999). Using a scale ranging from $1=$ not at all important to 5 = very important, adolescents responded to items such as, "Treat your parents with great respect”, "Follow your parents' advice about choosing friends”, and "Respect your older brothers and sisters”. The internal consistency was .80.

Family Obligation

Also found to be highly reliable in prior work (Fuligni et al. 1999; Fuligni et al. 2002), 12 items assessed attitudes toward family obligation or assistance. Youth reported the importance of each item on a five-point scale ranging from not at all to very with higher scores reflecting higher family obligation. Sample items include, "Help take care of brothers and sisters”, and, "Run errands that the family needs done”. Items concerning attitudes toward future support and obligation were also presented using a six-item scale. Samples include, "Help your parents financially in the future", and, "Spend time with your parents even after you no longer live with them". Consistent with prior research, current and future support scales were combined to reflect a single 18-item index of family obligation $(\alpha=.87)$.

Ethnic Identity

The Multigroup Ethnic Identity Measure (MEIM; Phinney 1992) measured ethnic identity. The belonging subscale consists of 5 items assessing ethnic pride, feeling good and happy about one's ethnic background, and feelings of belonging and attachment to one's ethnic group. Sample items read, "I am happy that I am a member of the group I belong to", and, "I have a lot of pride in my ethnic group”. The exploration subscale consists of 7 items and measures exploration of and commitment to one's ethnic group. Sample items read, "I have spent time trying to find out more about my ethnic group, such as its history, traditions, and customs", and, "I have a clear sense of my ethnic background and what it means for me". Items were scored on a 5-point scale ranging from strongly disagree to strongly agree with higher scores reflecting higher belonging and exploration ( $\alpha=.93$ and .75, respectively).

Results

Gender Differences in Academic Outcomes and Putative Mediators 
Independent samples t-tests first determined gender differences in academic outcomes, as well as in putative mediating variables. As shown in Table 1, girls reported significantly higher academic goals, intrinsic motivation, and utility value of school compared to boys. Girls also reported higher academic expectations than boys, but this difference was not statistically significant. There was evidence to implicate specific mediators of gender differences given that girls tended to also report higher levels of family respect, family obligation, and ethnic exploration compared to boys.

\section{Table 1}

Bivariate correlations and means (SDs) of variables among Asian adolescents

\begin{tabular}{|c|c|c|c|c|c|c|c|c|c|c|c|c|c|c|}
\hline & \multirow{2}{*}{ (1) } & \multirow{2}{*}{ (2) } & \multirow{2}{*}{ (3) } & \multirow{2}{*}{ (4) } & \multirow{2}{*}{ (5) } & \multirow{2}{*}{ (6) } & \multirow{2}{*}{ (7) } & \multirow{2}{*}{ (8) } & \multirow{2}{*}{ (9) } & \multirow{2}{*}{ (10) } & \multirow{2}{*}{ (11) } & \multicolumn{2}{|c|}{ Gender } & \multirow{2}{*}{$t$} \\
\hline & & & & & & & & & & & & $\begin{array}{l}\text { Femal } \\
\text { e }\end{array}$ & Male & \\
\hline \multicolumn{15}{|c|}{ Academic Adj. } \\
\hline $\begin{array}{l}\text { (1) Ed. } \\
\text { goals }\end{array}$ & - & & & & & & & & & & & $\begin{array}{l}4.55 \\
(.69)\end{array}$ & $\begin{array}{l}4.32 \\
(.85)\end{array}$ & $\begin{array}{l}1 . \\
96 \\
*\end{array}$ \\
\hline $\begin{array}{l}\text { (2) Ed. } \\
\text { expect. }\end{array}$ & $\begin{array}{l}.79 * * \\
*\end{array}$ & - & & & & & & & & & & $\begin{array}{l}4.21 \\
(.96)\end{array}$ & $\begin{array}{l}4.11 \\
(.93)\end{array}$ & $\begin{array}{l}.6 \\
8\end{array}$ \\
\hline $\begin{array}{l}(3) \\
\text { Intrinsic } \\
\text { mot. }\end{array}$ & .02 & $.18 *$ & - & & & & & & & & & $\begin{array}{l}2.80 \\
(1.01)\end{array}$ & $\begin{array}{l}2.49 \\
(1.07)\end{array}$ & $\begin{array}{l}1 . \\
96 \\
*\end{array}$ \\
\hline
\end{tabular}




\begin{tabular}{|c|c|c|c|c|c|c|c|c|c|c|c|c|c|c|}
\hline & \multirow{2}{*}{ (1) } & \multirow{2}{*}{ (2) } & \multirow{2}{*}{ (3) } & \multirow{2}{*}{ (4) } & \multirow{2}{*}{ (5) } & \multirow{2}{*}{ (6) } & \multirow{2}{*}{ (7) } & \multirow{2}{*}{ (8) } & \multirow{2}{*}{ (9) } & \multirow{2}{*}{ (10) } & \multirow{2}{*}{ (11) } & \multicolumn{2}{|l|}{ Gender } & \multirow{2}{*}{$t$} \\
\hline & & & & & & & & & & & & $\begin{array}{l}\text { Femal } \\
\text { e }\end{array}$ & Male & \\
\hline $\begin{array}{l}(4) \\
\text { Utility } \\
\text { value }\end{array}$ & $.28^{* *}$ & $\begin{array}{l}.27^{* *} \\
*\end{array}$ & $\begin{array}{l}.46^{* *} \\
*\end{array}$ & - & & & & & & & & $\begin{array}{l}4.19 \\
(.66)\end{array}$ & $\begin{array}{l}3.81 \\
(.90)\end{array}$ & $\begin{array}{l}3 . \\
19 \\
* *\end{array}$ \\
\hline
\end{tabular}

Ethnic identity

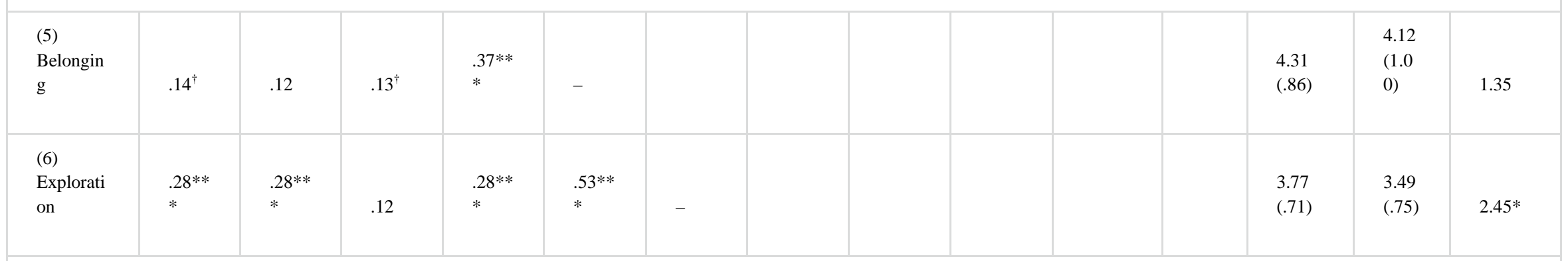

Family variables

\begin{tabular}{|c|c|c|c|c|c|c|c|c|c|c|c|}
\hline $\begin{array}{l}\text { (7) } \\
\text { Respect }\end{array}$ & $\begin{array}{l}.26^{* *} \\
*\end{array}$ & $\begin{array}{l}.29 * * \\
*\end{array}$ & $\begin{array}{l}.34^{* *} \\
*\end{array}$ & $\begin{array}{l}.51^{* *} \\
*\end{array}$ & $\begin{array}{l}.49^{* *} \\
*\end{array}$ & $\begin{array}{l}.42 * * \\
*\end{array}$ & - & & $\begin{array}{l}4.24 \\
(.60)\end{array}$ & $\begin{array}{l}3.87 \\
(.69)\end{array}$ & $\begin{array}{l}3.69 * * \\
*\end{array}$ \\
\hline $\begin{array}{l}(8) \\
\text { Obligatio } \\
n\end{array}$ & .09 & $.13^{\dagger}$ & $\begin{array}{l}.32^{* *} \\
*\end{array}$ & $\begin{array}{l}.38^{* *} \\
*\end{array}$ & $\begin{array}{l}.53^{* *} \\
*\end{array}$ & $\begin{array}{l}.49 * * \\
*\end{array}$ & $\begin{array}{l}.66^{* *} \\
*\end{array}$ & - & $\begin{array}{l}3.95 \\
(.59)\end{array}$ & $\begin{array}{l}3.71 \\
(.08)\end{array}$ & $2.45^{*}$ \\
\hline
\end{tabular}

School variables 


\begin{tabular}{|c|c|c|c|c|c|c|c|c|c|c|c|c|c|c|}
\hline & \multirow{2}{*}{ (1) } & \multirow{2}{*}{ (2) } & \multirow{2}{*}{ (3) } & \multirow{2}{*}{ (4) } & \multirow{2}{*}{ (5) } & \multirow{2}{*}{ (6) } & \multirow{2}{*}{ (7) } & \multirow{2}{*}{ (8) } & \multirow{2}{*}{ (9) } & \multirow{2}{*}{ (10) } & \multirow{2}{*}{ (11) } & \multicolumn{2}{|c|}{ Gender } & \multirow{2}{*}{$t$} \\
\hline & & & & & & & & & & & & $\begin{array}{l}\text { Femal } \\
\text { e }\end{array}$ & $\mathbf{M a}$ & \\
\hline $\begin{array}{l}\text { (9) Sch. } \\
\text { Centr. }\end{array}$ & $\begin{array}{l}.27^{* *} \\
*\end{array}$ & $\begin{array}{l}.31^{* *} \\
*\end{array}$ & $\begin{array}{l}.35 * * \\
*\end{array}$ & $\begin{array}{l}.53^{* *} \\
*\end{array}$ & $\begin{array}{l}.57^{* *} \\
*\end{array}$ & $\begin{array}{l}.35^{* *} \\
*\end{array}$ & $\begin{array}{l}.45^{* *} \\
*\end{array}$ & $\begin{array}{l}.33^{* *} \\
*\end{array}$ & - & & & $\begin{array}{l}3.69 \\
(.95)\end{array}$ & $\begin{array}{l}3.47 \\
(.97)\end{array}$ & 1.51 \\
\hline $\begin{array}{l}\text { (10) Sch. } \\
\text { conn. }\end{array}$ & $\begin{array}{l}.33^{* *} \\
*\end{array}$ & $\begin{array}{l}.36^{* *} \\
*\end{array}$ & $\begin{array}{l}.30 * * \\
*\end{array}$ & $\begin{array}{l}.38 * * \\
*\end{array}$ & $\begin{array}{l}.44 * * \\
*\end{array}$ & $\begin{array}{l}.31^{* *} \\
*\end{array}$ & $\begin{array}{l}.30^{* *} \\
*\end{array}$ & $.25^{* *}$ & $\begin{array}{l}.72^{* *} \\
*\end{array}$ & - & & $\begin{array}{l}3.38 \\
(1.02)\end{array}$ & $\begin{array}{l}3.53 \\
(.92)\end{array}$ & -1.01 \\
\hline $\begin{array}{l}(11) \\
\text { Discr. }\end{array}$ & $\begin{array}{l}-.15 \\
*\end{array}$ & $\begin{array}{l}-.17 \\
*\end{array}$ & -.05 & -.08 & $\begin{array}{l}-.19 * \\
*\end{array}$ & -.04 & -.02 & .12 & $\begin{array}{l}-.22 * \\
*\end{array}$ & $\begin{array}{l}-.26^{*} \\
* *\end{array}$ & - & $\begin{array}{l}2.30 \\
(.96)\end{array}$ & $\begin{array}{l}2.12 \\
(.88)\end{array}$ & 1.26 \\
\hline
\end{tabular}

Female $n=100$, male $n=72 .^{\dagger} p<.10, * p<.05, * * p<.01, * * * p<.001$ 
Bivariate Associations between Putative Mediators and Outcomes

Bivariate correlations examined links between academic adjustment and school, family, and cultural variables. Correlations in Table 1 suggest that associations were in expected directions. Specifically, school centrality and connectedness were each significantly and positively related to all four academic outcomes. Greater perceived discrimination was significantly linked to lower goals and expectations. Family respect was significantly and positively related to all four outcomes, and family obligation was significantly and positively associated with intrinsic motivation and utility value of school. Ethnic exploration was positively related to all four outcomes, but links with intrinsic motivation did not reach statistical significance. Ethnic belonging was also positively related to outcomes, but the association with utility value of school was the only one that was significant.

Mediation of Gendered Adjustment

Hierarchical regressions were used to examine whether the addition of putative mediators would reduce gender differences in academic adjustment. Statistical mediation was only examined for those variables that met criteria for mediation testing, as shown through preliminary analyses (Table 1) to demonstrate significant gender differences and correlations with outcomes. Hence, we did not include educational expectations as an outcome because t-tests did not demonstrate any initial gender differences. The first step in each model included only adolescent gender. The next step included possible family, school, and cultural mediators that were previously identified as being associated with academic outcomes as well as differentiated by gender (i.e., ethnic exploration, family respect, and family obligation).

As shown in Table 2, the first step of our models generally confirmed t-tests showing that girls report higher educational goals, intrinsic motivation, and utility value of school than boys. However, these initial gender effects were no longer significant once ethnic identity and family variables were taken into account. The bootstrapping procedure developed by Preacher and Hayes (2004) was used to formally test whether or not the inclusion of mediators statistically reduced gender differences in academic adjustment for girls versus boys. This procedure estimates direct, total, and indirect effects, and the statistical significance of indirect pathways (e.g., the difference between a direct association and the part of the association between gender and outcomes that is due to a third variable), and is particularly appropriate for our data as it suffers little loss of power when used with relatively small samples. For educational goals, the pathways that met criteria for mediation included those from adolescent gender via ethnic exploration and family respect. For intrinsic motivation, we examined indirect pathways through family respect and family obligation. All three mediators (e.g., ethnic exploration, family respect, family obligation) were examined for utility value of school. 


\section{Table 2}

Ethnic Identity and family variables as mediators of gendered academic adjustment among Asian adolescents

\begin{tabular}{|c|c|c|c|c|c|c|c|c|c|}
\hline & \multicolumn{3}{|c|}{ Ed. Goals } & \multicolumn{3}{|c|}{ Intrinsic motiv. } & \multicolumn{3}{|c|}{ Utility value sch. } \\
\hline & $\boldsymbol{b}$ & SE & $\boldsymbol{\beta}$ & $\boldsymbol{b}$ & $\mathrm{SE}$ & $\boldsymbol{\beta}$ & $\boldsymbol{b}$ & SE & $\boldsymbol{\beta}$ \\
\hline \multicolumn{10}{|l|}{ Step 1} \\
\hline Gender & -.24 & .12 & $-.16^{*}$ & -.27 & .16 & $-.13^{\dagger}$ & -.37 & .12 & $-.23^{* *}$ \\
\hline \multicolumn{10}{|l|}{ Step 2} \\
\hline Gender & -.12 & .12 & -.08 & -.08 & .16 & -.04 & -.15 & .11 & -.09 \\
\hline Eth. explor. & .20 & .08 & $.19^{*}$ & - & - & - & .06 & .08 & .06 \\
\hline Fam. respect & .18 & .10 & $.15^{\dagger}$ & .34 & .15 & $.22 *$ & .51 & .11 & $.43 * * *$ \\
\hline Fam. oblg. & - & - & - & .29 & .16 & $.18^{\dagger}$ & .08 & .12 & .06 \\
\hline $\begin{array}{l}\text { Step } 1 R^{2} \text {;Step } 2 \\
\Delta R^{2}\end{array}$ & \multicolumn{3}{|c|}{$.02 * ; .08^{* * *}$} & \multicolumn{3}{|c|}{$.02^{\dagger} ; .12^{* * *}$} & \multicolumn{3}{|c|}{$.05^{* *} ; .23^{* * *}$} \\
\hline
\end{tabular}

Family obligation was not examined as a mediator of gender differences in educational goals because correlations did not support a bivariate association between obligation and goals. Ethnic exploration was not examined as a mediator of gender differences in intrinsic motivation

${ }^{\dagger} p<.10, * p<.05, * * p<.01, * * * p<.001$

In terms of academic goals, bootstrapping procedures confirm the statistical significance of mediating pathways. The resulting indirect effects of gender through ethnic exploration $(b=-.073, p<.06$; bootstrapped $95 \%$ CI ranging from -.156 to -.011 ) and through family respect $(b=-.097, p<.05 ; 95 \% \mathrm{CI}-.189$ to -.024 ) further suggest that family respect is the most effective mediator of gender differences in goals. Significant indirect effects were also observed for intrinsic motivation. The indirect effect of gender on intrinsic motivation via family respect $(b=-.189 p<.01 ; 95 \% \mathrm{CI}-.338$ to -.066$)$ was statistically significant as was the 
indirect pathway via family obligation ( $b=-.124, p<.05 ; 95 \% \mathrm{CI}-.240$ to -.029$)$. Finally, when considering indirect pathways from gender to utility value of school, there were significant gender effects through respect $(b=-.212, p<.01,95 \% \mathrm{CI}-.381$ to -.084$)$ and obligation $(b=-.108, p<.05 ; 95 \% \mathrm{CI}-.228$ to -.023$)$, but not ethnic exploration. Thus, although ethnic exploration and family obligation both played mediating roles, family respect appears to be the most consistent and prominent mediator of gendered academic outcomes.

Discussion

Differential patterns of academic achievement have been consistently demonstrated among boys and girls from immigrant backgrounds (Qin 2006; Suárez-Orozco and Qin 2005). Yet, specific mechanisms to help explain such gendered patterns of outcomes have not been empirically tested. What is more, changing demographics and a limited focus on adolescents' academic experiences among emerging immigrant communities highlight the need to broaden the literature, especially since these contexts may present unique experiences and academic struggles for adolescents that may potentially hamper their successful adaptation (Bailey 2005; Perreira et al. 2010; Smith-Adcock et al. 2006). In the current study, we utilized data from Asian adolescents recruited from a community that is newly adjusting to having an immigrant population to determine whether similar patterns of gendered academic adjustment can be found among understudied regions of the US. Given that education and academic adjustment are critical indicators of adolescents' success and eventual socioeconomic mobility, it is crucial to better understand the factors that may help or hinder immigrant adolescents' achievement and motivation (Eccles et al. 1993; Suárez-Orozco et al. 2010).

Consistent with prior research (Qin 2006; Suárez-Orozco and Qin 2005), Asian American girls in our sample reported higher educational goals, intrinsic motivation, and utility value of school compared to boys. Basic patterns of academic adjustment among adolescents residing in an emerging immigrant community thus appear similar to patterns found in more traditionallystudied areas of the US, providing some support for the generalizability of how gender may differentiate adolescents' academic success. Because we do not have a comparison sample of adolescents from a more traditional area of migration, it is difficult to directly compare the magnitude of gender differences that may be found across contexts. It thus remains unclear whether the gender differences found here are relatively larger or smaller than those found in more urban areas of the US. Nonetheless, the fact that academic outcomes were significantly differentiated by gender among new immigrant communities suggests that some processes, such as those stemming from the educational system, may be rather robust, transcending geographic context and reflecting a broadly generalizable experience for immigrant youth.

In addition to examining basic links between gender and academic outcomes, we also investigated how a variety of school, family, and cultural variables may be associated with 
adjustment and ultimately mediate the gender differences that were found. At the bivariate level, results supported positive effects of positive school experiences. Specifically, in line with prior research (Libbey 2004; Marchant et al. 2001; Roeser et al. 2000), youth who felt positively about and strongly connected to their schools (e.g., via centrality of being a student, school connectedness) tended to also report higher academic goals, expectations, motivation, and utility value of school. Greater perceptions of discrimination were also linked with lower educational goals and expectations, suggesting that perceptions of ethnic bias may limit academic accomplishments. These results are even more striking given that youth were not asked to think about school-based discrimination per se. It is possible that adolescents naturally reflected on school-based discrimination, but because our measure asked about discrimination experiences in general, some reports could have been based on experiences outside of the school context. More targeted measures of school-based discrimination could have produced even stronger associations; clearly, more research on this topic would be informative.

Bivariate associations also supported positive effects of family relationships and ethnic identity. Consistent with existing research on family influences (Fuligni et al. 1999), adolescents who reported high degrees of family respect and family obligation tended to also report more adaptive academic outcomes. Perhaps family connectedness encourages greater attention to schoolwork and limits participation in potentially risky activities outside of the home, subsequently leading to more positive academic outcomes (Zhou and Bankston 2001). With respect to ethnic identity, ethnic belonging was associated with higher utility value of school, and ethnic exploration was associated with higher utility value, as well as educational goals and expectations. These results provide additional support for prior work demonstrating positive effects of ethnic identity that pervade into the academic arena (Fuligni et al. 2005; Vargas-Reighley 2005).

Taken together, academic adjustment appears to be regulated by a number of variables that stem from diverse contexts of school, family, and culture, indicating that programs or interventions designed to boost academic success may be most beneficial if multiple domains of influence are targeted. For example, feeling strongly attached to one's school appeared to have the strongest and most consistent bivariate associations with academic outcomes. It seems particularly important for parents, teachers, counselors, and other school administrators and personnel to promote adolescents connectedness to their school (e.g., engaging shy students, encouraging advanced placement courses), especially among emerging immigrant settlement areas where immigrant youth are in the ethnic minority, may feel like cultural outsiders, and may perceive messages that hinder their academic success. Fostering family relationships and strengthening ethnic ties could help adolescents cope with stressful cultural experiences, such as discrimination, as well as directly increase academic adjustment.

Although most of the school, family, and cultural variables that were implicated in this study were significantly related to academic adjustment at the bivariate level, some were not differentiated by gender, precluding further mediational tests. Family respect, obligation, and ethnic exploration did meet these criteria (e.g., significant associations with both gender and 
outcomes) and were examined as putative mediators of gender differences in educational goals, intrinsic motivation, and valuing of the utility of school. Evidence for mediation was found for ethnic exploration and family respect, which notably appeared to subsume the effect of obligation. That is, even though family obligation was associated with academic adjustment at the bivariate level, family respect appeared to be a more prominent mediator of gendered effects. Hence, family respect seems to play a particularly significant role in explaining why girls tend to exhibit healthier academic adjustment than boys. The importance of the family in contributing to academic outcomes is consistent with prior work demonstrating that parental connection or closeness, family cohesion, and resource sharing tends to be associated with positive adolescent adjustment (Juang and Nguyen 2010; Juang et al. 2007; Kiang and Fuligni 2009).

Collectively, these mediational results suggest that one possible strategy to minimize gender disparities in academic adjustment is to encourage positive family relationships among boys. Given that close familial ties seem to foster more adaptive academic outcomes, it may be worthwhile in future research to pinpoint why gender differences in family respect exist to begin with and to subsequently target those areas for change. For instance, are such gender differences the result of differential parent socialization strategies? Are they due to broader societal expectations whereby boys are granted more social freedom than girls and, for example, encouraged to be more independent from the family? Knowing that family respect appears to be stronger for girls than for boys, parents could be encouraged to increase their monitoring of sons' behaviors, and ultimately strengthen their relationships. In turn, these improvements could serve to increase boys' academic motivation and success.

Although we addressed a gap in the existing literature by targeting adolescents who reside in an understudied region of the US, generalizability to adolescents in other regions is limited. Similarly, by recruiting from emerging immigrant communities, our sample included a relatively large number of adolescents from Southeast Asian backgrounds. Although this serves to extend our understanding to understudied youth, our sample was panethnic in nature and represented groups that were too small for meaningful sub-ethnic comparisons. Clearly, further research that examines larger and more diverse samples, which could allow for the examination of inter- and intra-ethnic variability, would be worthwhile to shed more light on the patterns of academic adjustment found among immigrant youth. Yet, given the relatively "new” population studied here, acquiring large samples in areas with growing immigrant populations that are still rather small in total population is a challenge.

Another limitation of the current study is that all of the results were based on single-surveyed and correlational accounts, which preclude any conclusive interpretations regarding the directionality of effects. It would be necessary for future research to incorporate longitudinal models of academic trajectories, as Suárez-Orozco et al. (2010) have done, to better understand how developmental processes, such as those found in family relationships, ethnic identity, and school experiences, may change and interact over time. It is also notable that the current study recruited adolescents in the 9th and 10th grades, who have recently experienced the transition to 
high school. Perhaps academic experiences are particularly salient and vulnerable during these key transitions and, as such, it may be important for future research on academic adjustment to consider similar transitions to school, potentially extending our understanding of immigrant academic adjustment to the crucial college transition as well (Supple et al. 2010).

Despite our findings that females report relatively more success in the academic domain than males, it is noteworthy to keep in mind that girls are not immune to academic failure. Abundant research demonstrates that adolescents from ethnic minority backgrounds, regardless of gender, face numerous obstacles and barriers to academic achievement (Suárez-Orozco et al. 2010). In fact, given differences in social expectations that may stem from both school and family domains, girls may face added pressure to achieve and to do well, which may have a backlash in terms of actual success (Qin 2006). Researchers and school personnel should thus be cautioned to not overlook the potential struggles that girls may face within the academic arena.

The delicate nature of adolescence in determining academic success or unsuccessful trajectories (Eccles et al. 1993) highlights the importance of further research to better understand how diverse factors in immigrant adolescents' lives may contribute to their academic outcomes, including demographic variables such as gender as well as putative mediators that stem from multiple sociocultural domains. Our results point to gender differences in adolescent family relationships and in ethnic identity as mechanisms that help explain gender disparities in academic adjustment, suggesting that efforts to increase boys' family closeness and ethnic identity could also help to increase their levels of academic engagement to equal their female peers. Particularly among emerging immigrant communities, where resources that encourage immigrant adolescents' academic success may be already limited, it seems especially crucial to continue identifying specific ways to foster adolescent development and adaptation, for both boys and girls.

\section{References}

Bailey, R. (2005). New immigrant communities in the North Carolina Piedmont Triad: Integration issues and challenges. In E. M. Gozdziak \& S. F. Martin (Eds.), Beyond the gateway: Immigrants in a changing America (pp. 57-86). Lanham: Lexington Books.

Brandon, P. R. (1991). Gender differences in young Asian Americans' educational attainments. Sex Roles, 25(1-2), 45-61. doi:10.1007/BF00289316.

Bronfenbrenner, U. (1979). The ecology of human development: Experiments by nature and design. Cambridge, MA: Harvard University Press.

Brown, R., \& Evans, W. P. (2002). Extracurricular activity and ethnicity: Creating greater school connection among diverse student populations. Urban Education, 37(1), 41-58. 
US Census. (2004). Vintage 2004 archive. Retrieved on 12 Jan 2007. From www.census.gov/popest/archives/2000s/vintage_2004.

US Census. (2011). Overview of race and hispanic origin: 2010. Retrieved 2 June 2011. From http://www.cdc.gov.nchs/data/hus/hus07.pdf.

Chun, K. (1995). The myth of Asian American success and its educational ramifications. In D. T. Nakanishi \& T. Y. Nishida (Eds.), The Asian American educational experience: A sourcebook for teachers and students (pp. 95-112). New York: Routledge.

Cooley, C. H. (1902). Human nature and the social order. New York: Scribners.

Dotson-Blake, K. P., Foster, V. A., \& Gressard, C. F. (2009). Ending the silence of the Mexican immigrant voice in public education: Creating culturally inclusive family-school-community partnerships. Professional School Counseling, 12(3), 23-230.

Eccles, J. S. (1983). Expectancies, values, and academic behaviors. In J. T. Spence (Ed.), Achievement and achievement motivation (pp. 75-146). San Francisco, CA: Freeman.

Eccles, J. S., Midgley, C., Wigfield, A., Buchanan, C., Reuman, D., Flanagan, C., et al. (1993). Development during adolescence: The impact of stage-environment fit on young adolescents' experiences in schools and in families. American Psychologist, 48(2), 90-101.

Fuligni, A. J., Tseng, V., \& Lam, M. (1999). Attitudes toward family obligations among American adolescents from Asian, Latin American, and European backgrounds. Child Development, 70, 1030-1044.

Fuligni, A. J., Yip, T., \& Tseng, V. (2002). The impact of family obligation on the daily behavior and psychological well being of Chinese American adolescents. Child Development, 73, 302314.

Fuligni, A. J., Witkow, M. R., \& Garcia, C. (2005). Ethnic identity and the academic adjustment of adolescents from Mexican, Chinese, and European backgrounds. Developmental Psychology, 41, 799-811.

Greene, M. L., Way, N., \& Pahl, K. (2006). Trajectories of perceived adult and peer discrimination among Black, Latino and Asian American adolescents: Patterns and psychological correlates. Developmental Psychology, 42(2), 218-238.

Juang, L. P., \& Nguyen, H. H. (2010). Ethnic identity among Chinese-American youth: The role of family obligation and community factors on ethnic engagement, clarity, and pride. Identity: An International Journal of Theory and Research, 1, 20-38. 
Juang, L. P., Syed, M., \& Takagi, M. (2007). Intergenerational discrepancies of parental control among Chinese American families: Links to family conflict and adolescent depressive symptoms. Journal of Adolescence, 30, 965-975.

Kiang, L., \& Fuligni, A. J. (2009). Ethnic identity and family processes among adolescents from Latin American, Asian, and European backgrounds. Journal of Youth and Adolescence, 38, 228241.

Kiang, L., Yip, T., \& Fuligni, A. J. (2008). Multiple identities and adjustment in ethnically diverse young adults. Journal of Research on Adolescence, 18, 643-670.

Klem, A. M., \& Connell, J. P. (2004). Relationships matter: Linking teacher support to student engagement and achievement. Journal of School Health, 74, 262-273.

Lane, K., Pierson, M. R., \& Givner, C. C. (2003). Teacher expectations of student behavior: Which skills do elementary and secondary teachers deem necessary for success in the classroom? Education \& Treatment of Children, 26(4), 413-430.

LaRusso, M. D., Romer, D., \& Selman, R. L. (2008). Teachers as builders of respectful school climates: Implications for adolescent drug use norms and depressive symptoms in high school. Journal of Youth and Adolescence, 37(4), 386-398.

Lee, J. C., \& Stacey, J. (2001). More than 'model minorities' or 'delinquents': A look at Hmong American high school students. Harvard Educational Review, 71, 505-528.

Libbey, H. P. (2004). Measuring student relationships to school: Attachment, bonding, connectedness, and engagement. Journal of School Health, 74, 274-283.

Lopez, N. (2003). Hopeful girls, troubled boys: Race and gender disparity in urban education. New York: Routledge.

Marchant, G. J., Paulson, S. E., \& Rothlisberg, B. A. (2001). Relations of middle school students' perceptions of family and school contexts with academic achievement. Psychology in the Schools, 38(6), 505-519. doi:10.1002/pits.1039.abs.

Massey, D. S., \& Capoferro, C. (2008). The geographic diversification of American immigration. In D. S. Massey (Ed.), New faces in new places: The changing geography of American immigration (pp. 25-50). New York: Russell Sage.

Migration Policy Institute. (2008). States ranked by percent change in the foreign-born population: 1990, 2000, and 2008. Retrieved 1 Dec 2009 from http://www.migrationinformation.org/dataHub/acscensus.cfm.

Ngo, B., \& Lee, S. J. (2007). Complicating the image of model minority success: A review of south east Asian American education. Review of Educational Research, 77(4), 415-453. 
Olsen, L. (1997). Made in America: Immigrant students in our public schools. New York: The New Press.

Parrado, E. A., \& Kandel, W. (2008). New Hispanic migrant destinations: A tale of two industries. In D. S. Massey (Ed.), New faces in new places: The changing geography of American immigration (pp. 99-123). New York: Russell Sage.

Perreira, K. M., Fuligni, A. J., \& Potochnick, S. (2010). Fitting in: The roles of social acceptance and discrimination in shaping the academic motivations of Latino youth in the US Southeast. Journal of Social Issues, 66, 131-153.

Phinney, J. S. (1992). The multigroup ethnic identity measure: A new scale for use with diverse groups. Journal of Adolescent Research, 7, 156-176.

Portes, A., \& Rumbaut, R. G. (2001). Legacies: The story of the immigrant second generation. New York: Russell Sage Foundation.

Preacher, K. J., \& Hayes, A. F. (2004). SPSS and SAS procedures for estimating indirect effects in simple mediation models. Behavior Research Methods, Instruments \& Computers, 36(4), 717731.

Qin, D. B. (2003). Gendered expectations and gendered experiences: Immigrant students’ adaptation in school. New Directions in Youth Development Special Issue: The Social Worlds of Immigrant Youth, 100, 91-100.

Qin, D. (2006). The role of gender in immigrant children's educational adaptation. Current Issues in Comparative Education, 9(1), 8-19.

Roeser, R. W., Eccles, J. S., \& Sameroff, A. J. (2000). School as a context of early adolescents' academic and social-emotional development: A summary of research findings. The Elementary School Journal, 100(5), 443-471. doi:10.1086/499650.

Rong, X. L., \& Brown, F. (2001). The effects of immigrant generation and ethnicity on educational attainment among young African and Caribbean Blacks in the United States. Harvard Educational Review 70, 537-565.

Rosenbloom, S., \& Way, N. (2004). Experiences of discrimination among African American, Asian American, and Latino Americans in an urban high school. Youth and Society, 35, 420451.

Ryan, A. M., \& Patrick, H. (2001). The classroom social environment and changes in adolescents' motivation and engagement during middle school. American Educational Research Journal, 38(2), 437-460. doi:10.3102/00028312038002437. 
Smith-Adcock, S., Daniels, M., Lee, S., Villalba, J., \& Indelicato, N. (2006). Culturally responsive school counseling for Hispanic/Latino students and families: The need for bilingual school counselors. Professional School Counseling, 10(1), 92-101.

Stanton-Salazar, R. D. (2001). Manufacturing hope and despair: The school and kin support networks of US-Mexican youth. New York: Teachers College Press.

Suárez-Orozco, C., \& Qin, D. B. (2005). Gendered perspectives in psychology: Immigrant origin youth. International Migration Review, 40, 165-198.

Suárez-Orozco, C., Pimentel, A., \& Martin, M. (2009). The significance of relationships: Academic engagement and achievement among newcomer immigrant youth. Teachers College Record, 111, 5-6.

Suárez-Orozco, C., Gaytán, F. X., Bang, H., Pakes, J., O’Connor, E., \& Rhodes, J. (2010). Academic trajectories of newcomer immigrant youth. Developmental Psychology, 46(3), 602618. doi:10.1037/a0018201.

Sue, S., \& Okazaki, S. (1990). Asian-American educational achievements: A phenomenon in search of an explanation. American Psychologist, 45(8), 913-920.

Supple, A. J., Ghazarian, S. R., Frabutt, J. M., Plunkett, S. W., \& Sands, T. (2006). Contextual influences on Latino adolescent ethnic identity and academic outcomes. Child Development, 77(5), 1427-1433. doi:10.1111/j.1467-8624.2006.00945.x.

Supple, A. J., McCoy, S. Z., \& Wang, Y. (2010). Parental influences on Hmong university students’ success. Hmong Studies Journal, 11, 1-37.

Suzuki, B. H. (2002). Revisiting the model minority stereotype: Implications for student affairs practice and higher education. New Directions for Student Services, 97, 21-32.

Vargas-Reighley, R. (2005). Bi-cultural competence and academic resilience among immigrants. New York: LFB Scholarly Publishers.

Way, N., \& Robinson, M. (2003). The influence of family and friends on the psychological adjustment of ethnic minority, low-income adolescents. Journal of Adolescent Research, 18, 324-347.

Wong, F., \& Halgin, R. (2006). The "model minority": Bane or blessing for Asian Americans? Journal of Multicultural Counseling and Development, 34(1), 38-49.

Xiong, Z., Eliason, P. A., Detzner, D. F., \& Cleveland, M. J. (2005). Southeast Asian immigrants' perceptions of good adolescents and good parents. Journal of Psychology: Interdisciplinary and Applied, 139(2), 159-175. doi:10.3200/JRLP.139.2.159-175. 
Yang, K. (2003). Hmong Americans: A review of felt needs, problems, and community development. Hmong Studies Journal, 4, 1-23.

Yip, T., Seaton, E. K., \& Sellers, R. M. (2006). African American racial identity across the lifespan: Identity status, identity content, and depressive symptoms. Child Development, 77, 1504-1517.

Zhou, M., \& Bankston, C. L., I. I. I. (2001). Family pressure and the educational experience of the daughters of Vietnamese refugees. International Migration, 39, 133-151. 